\title{
ISOLATION AND CHARACTERIZATION OF ANTIOXIDANT (FLAVONE-3-RUTINOSIDE, 3, 3', 4', 5, 7-PENTAHYDROXY) FROM LEAVES OF MELIA DUBIA
}

\author{
DAYANA JEYALEELA $\mathrm{G}^{1 *}$, BALASUBRAMANI N² , DR. ROSALINE VIMALA J ${ }^{1}$ \\ ${ }^{1}$ Department of Chemistry, Holy Cross College (Autonomous), Tiruchirappalli, Tamil Nadu, India. ${ }^{2}$ Department of Chemistry, \\ St. Joseph's College, Tiruchirappalli, Tamil Nadu, India. E-mail: princedayana1221@gmail.com
}

Received: 10 July2018, Revised and Accepted: 27 September 2018

\section{ABSTRACT}

Objective: Various antioxidants are extensively found at different levels in many medicinal plants. This study mainly focuses on identification and separation of antioxidant from the leaf extract of Melia dubia.

Materials and Methods: Soxhlet extraction adopted for extraction using solvents, namely hexane, chloroform, ethyl acetate, 70\% Ethanol, methanol, and water. The antioxidant capacity of six extracts was analyzed by quick and convenient 1, 1-diphenyl-2-picrylhydrazyl method. The compound responsible for high scavenging activity was isolated and separated by chromatography techniques such as thin-layer chromatography and highperformance liquid chromatography. Antioxidant was characterized by UV-visible, Fourier-transform infrared (FT-IR), $\mathrm{H}^{1}$-nuclear magnetic resonance (NMR), $\mathrm{C}^{13}$-NMR, and mass spectroscopy.

Results and Discussion: On extraction, water extract shows the highest yield percentage followed by methanol and $70 \%$ ethanol. Based on our results, $\mathrm{IC}_{50}$ value among the extracts, methanol and $70 \%$ ethanol, showed high antioxidant activity. Antioxidant which is commonly present in the methanol and 70\% ethanol extract is flavone-3-rutinoside, 3, 3', 4', 5, 7-pentahydroxy.

Conclusion: The occurrence of the antioxidant, i.e. rutin flavonoid was identified in the study, and the biological activity of this compound will determine in future work.

Key words: Soxhlet extraction, 1, 1-diphenyl-2-picrylhydrazyl assay, Thin-layer chromatography and high-performance liquid chromatography, Characterization, flavone-3-rutinoside, 3, 3', 4', 5, 7-pentahydroxy.

(c) 2019 The Authors. Published by Innovare Academic Sciences Pvt Ltd. This is an open access article under the CC BY license (http://creativecommons. org/licenses/by/4. 0/) DOI: http://dx.doi.org/10.22159/ajpcr.2019.v12i2.28384

\section{INTRODUCTION}

An antioxidant is a compound that inhibits the process of oxidation or delays some types of cell damage. Oxidation is a chemical reaction that can create free radicals, leading to chain reactions that may damage cells [1]. Molecules, atoms, or ions with unpaired electrons are known as free radicals. They are highly unstable and active toward chemical reactions with other molecules and derived from oxygen, nitrogen, and sulfur, thus creating reactive oxygen species (ROS), reactive nitrogen species, and reactive sulfur species. ROS include free radicals such as the superoxide anion $\left.\left(\mathrm{O}_{2}\right)^{-}\right)$. These free radicals react rapidly with the membranes eventually causing cellular degeneration and finally lead to death [2]. The generation of free radicals through lipid peroxidation is caused due to the continuous usage of the same vegetable oil which is not even properly stored and by reusing the already fried oil (rancid). The reason sometimes could be economic, but then it is highly damaging to the health. Nowadays, smoking and chronic alcoholism are creating health problem, and it reduces many important antioxidants in the serum which is detrimental to the health. Reports say that the proper intake of antioxidants will be quenching all these inevitably free radicals present in the body and thus improving the health by lowering the risk of various diseases [3,4]. The importance of the antioxidant constituents of plant materials in the maintenance of health and protection from diseases and also it raising interest among scientists, food manufacturers, and consumers as the trend of the future are moving toward functional food with specific health effects [5]

Potential sources of antioxidant compounds have been searched in several parts of plant materials such as vegetables, fruits, leaves, oilseeds, cereal crops, barks and roots, spices and herbs, and crude plant drugs. Beta-carotene, lutein, lycopene, selenium, and Vitamins
A, C, and $\mathrm{E}$ are the available antioxidant in recent days. High-dose supplements of the above antioxidants may be linked to health risks. For example, high doses of beta-carotene may increase the risk of lung cancer in smokers. High doses of Vitamin E may increase the risks of prostate cancer and one type of stroke. Antioxidant supplements may also interact with some medicines. For the health risk instead of using this already available anti-oxidant, flavonoid and phenolic compounds can provide an alternate source for antioxidant $[6,7]$.

Flavonoids and other phenolics have been suggested to play a preventive role in the development of diseases such as cancer and heart disease. Flavonoids and other plant phenolics, such as phenolic acids, stilbenes, tannins, lignans, and lignin, are, especially, common in leaves, flowering tissues, and woody parts such as stems and barks [8]. Flavonoids also partly provide plant colors present in flowers, fruits, and leaves and it generally occurs as glycosylated derivatives in plants, although conjugation with inorganic sulfate or organic acid. The antioxidant activity of phenolics is mainly due to their redox properties that act as reducing agents, hydrogen donators, and singlet oxygen quenchers and also have a metal chelation potential [9].

Antioxidant uses are being extensively studied in pharmacology, more specifically in the treatment of cancer, stroke, cardiovascular and neurodegenerative diseases, and certain diabetic complications. Antioxidants are also helping in protecting the skin from sun exposure roughness, wrinkle depth, ultraviolet-induced skin cancer, and skin swelling from sunlight. Hence, these antioxidants are used in body lotions creams, so as to protect the skin from sunlight. Antioxidants are used as food additives to help guard against food deterioration. A common use is as stabilizers in fuels and lubricants to prevent oxidation and in gasoline to prevent the polymerization that leads 
Table 1: Result of the extracts yield

\begin{tabular}{llll}
\hline S.No & Extracted solvent & Yield (g) & Yield (\%) \\
\hline 1 & Hexane & $0.3810 \pm 0.01522$ & 1.52 \\
2 & Chloroform & $0.8242 \pm 0.0145$ & 3.30 \\
3 & Ethyl acetate & $0.9091 \pm 0.0274$ & 3.64 \\
4 & Methanol & $1.6942 \pm 0.00615$ & 6.78 \\
5 & Water & $2.9477 \pm 0.04115$ & 11.79 \\
6 & $70 \%$ Ethanol & $1.4235 \pm 0.11815$ & 5.69 \\
\hline
\end{tabular}

Table 2: Result of the antioxidant activity on different extracts of MD leaves

\begin{tabular}{|c|c|c|c|c|c|c|c|}
\hline \multirow[t]{2}{*}{ S.NO } & \multirow[t]{2}{*}{ MD leaves } & \multicolumn{5}{|c|}{$\begin{array}{l}\text { Sample concentration and the } \\
\text { percentage of inhibition } \\
(\mu \mathrm{g} / \mathrm{mL})\end{array}$} & \multirow[t]{2}{*}{$\begin{array}{l}\mathrm{IC}_{50} \text { value } \\
\mu \mathrm{g} / \mathrm{mL}\end{array}$} \\
\hline & & 25 & 50 & 100 & 200 & 400 & \\
\hline 1 & Hexane & 1.99 & 7.87 & 10.89 & 34.51 & 66.23 & $120.78 \pm 0.445$ \\
\hline 2 & Chloroform & 11.77 & 16.70 & 32.08 & 33.70 & 50.77 & $74.84 \pm 0.350$ \\
\hline 3 & Ethyl acetate & 12.60 & 19.42 & 24.28 & 48.12 & 65.05 & $53.89 \pm 0.890$ \\
\hline 4 & $70 \%$ Ethanol & 26.80 & 38.12 & 58.43 & 85.08 & 91.71 & $17.47 \pm 29315$ \\
\hline 5 & Methanol & 15.60 & 47.97 & 84.77 & 94.33 & 93.52 & $15.61 \pm 0.1845$ \\
\hline 6 & Water & 14.22 & 19.55 & 23.48 & 31.29 & 46.90 & $86.30 \pm 0.4897$ \\
\hline
\end{tabular}

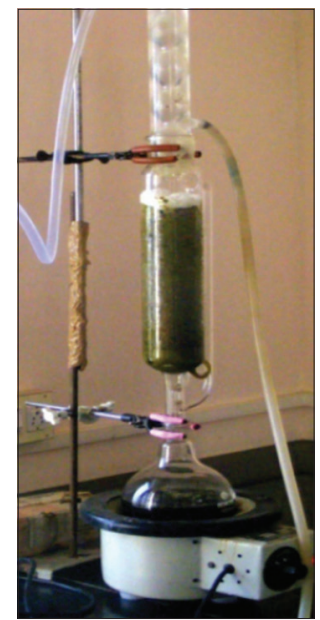

Fig. 1: Extraction by Soxhlet method

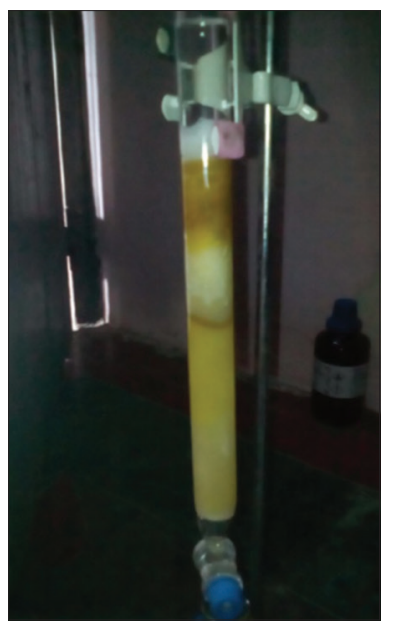

Fig. 2: Isolation of antioxidant by column chromatography

to the formation of engine-fouling residues. They are widely used to prevent the oxidative degradation of polymers such as rubbers,

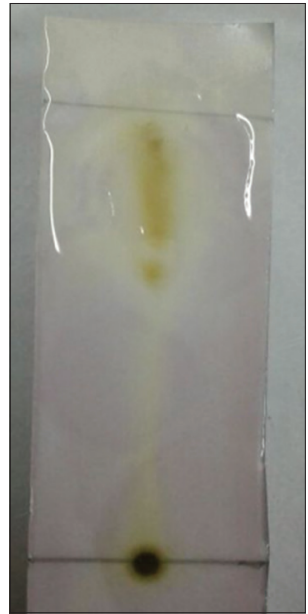

Fig. 3: Before spraying 1, 1-diphenyl-2-picrylhydrazyl reagent

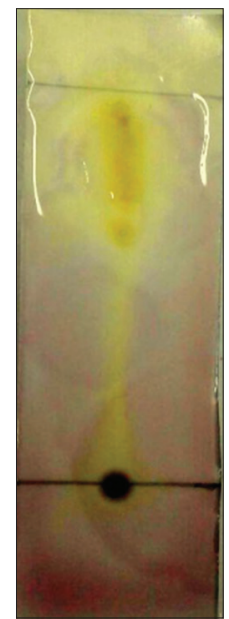

Fig. 4: After spraying 1, 1-diphenyl-2-picrylhydrazyl reagent

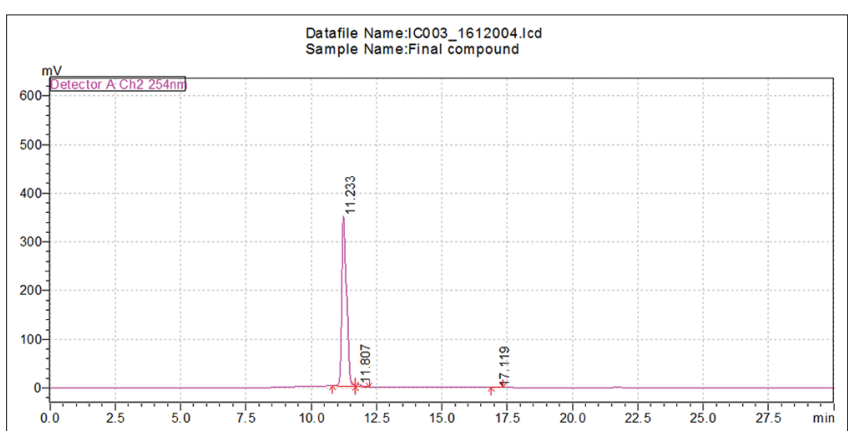

Fig. 5: High-performance liquid chromatography spectrum of antioxidant

plastics, and adhesives that causes a loss of strength and flexibility in these materials $[10,11]$.

Melia dubia is the medicinal plant, which is available in all seasons and possesses very good medicinal values in the Indian system. Recent days, it was used in the treatment of dengue fever in Tamil Nadu, India. Most of the people are employ number of methods for the isolation and characterization of compounds from plants or crude extracts, but this study aimed to isolate only bioactive compounds, especially antioxidant. This study mainly focuses on the identification and separation of antioxidant from the leaves of $M$. dubia, and before isolation process, the antioxidant activity of the all the extracts will be evaluated by 


\begin{tabular}{|r|r|r|r|r|r|}
\hline \hline Name & Ret. Time & \multicolumn{1}{|c|}{ Area } & Relative Retention Time & Height & \multicolumn{1}{c|}{ Area\% } \\
\hline & 13.050 & 29539 & - & 4295 & 0.1143 \\
\hline & 13.969 & 137233 & - & 15034 & 0.5311 \\
\hline & 14.349 & 35681 & - & 3576 & 0.1381 \\
\hline & 15.462 & 20358456 & - & 2618390 & 78.7876 \\
\hline & 15.597 & 5188043 & - & 858852 & 20.0778 \\
\hline & 16.616 & 63752 & - & 8992 & 0.2467 \\
\hline & 16.925 & 26980 & - & 4323 & 0.1044 \\
\hline
\end{tabular}

Fig. 6: High-performance liquid chromatography peak data results of antioxidant

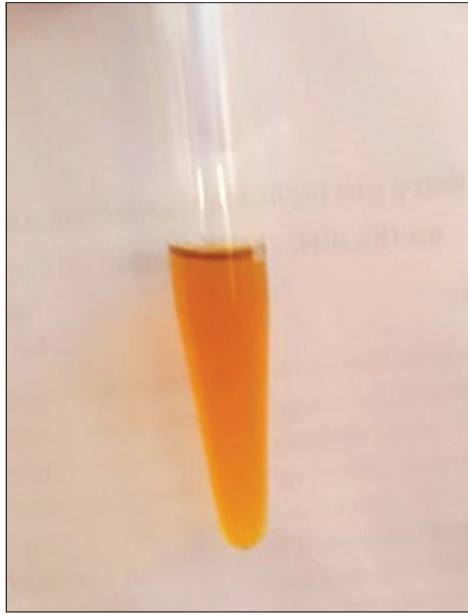

Fig. 7: The positive result of flavonoid test - A

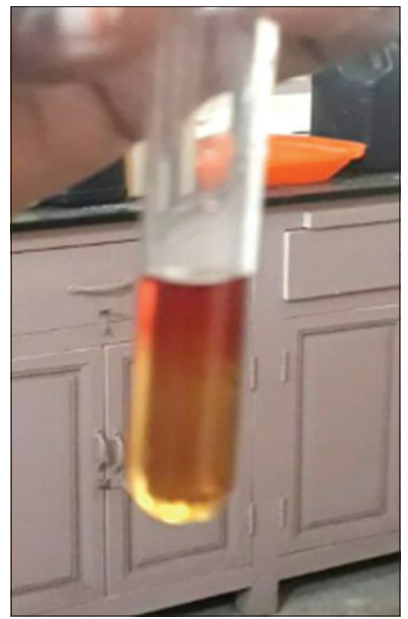

Fig. 8: The positive result of flavonoid test - B

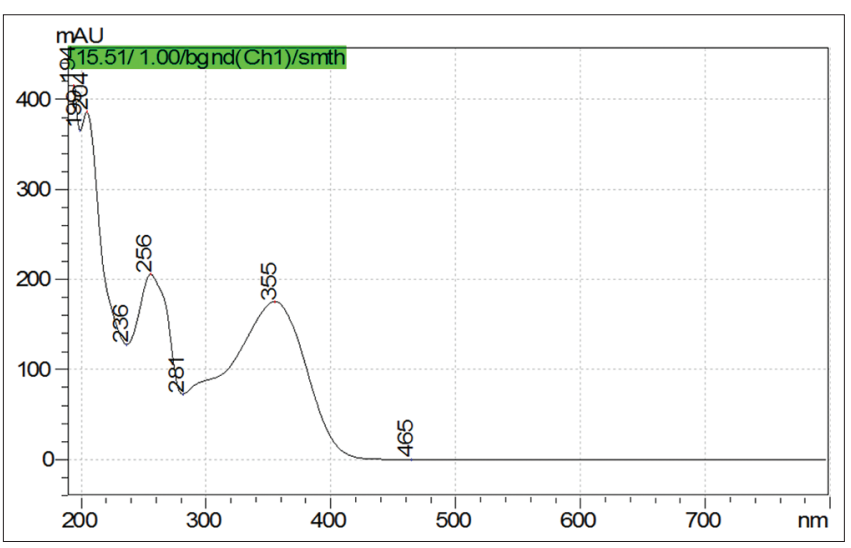

Fig. 9: UV-visible spectrum of antioxidant compound
Table 3: MSMS data of $\mathrm{m} / \mathrm{z}$ 611(+ve) under different collision energies using ESI-positive ionization

\begin{tabular}{|c|c|c|c|c|c|c|}
\hline \multirow{2}{*}{$\begin{array}{l}\text { Collision energy } \\
-5\end{array}$} & \multicolumn{6}{|c|}{ MS-MS fragmentation of M/Z 611 (+VE) } \\
\hline & 611 & 465 & 345 & 303 & & \\
\hline-10 & 611 & 465 & 345 & 303 & & \\
\hline-15 & 611 & 465 & 345 & 303 & & \\
\hline-25 & & 464 & 345 & 303 & 85 & \\
\hline-35 & & & & 303 & 85 & 71 \\
\hline-45 & & & & 303 & 85 & 71 \\
\hline-55 & & & 345 & 303 & 85 & 71 \\
\hline-60 & & & & 303 & 85 & 71 \\
\hline
\end{tabular}

ESI: Electrospray ionization

Table 4: MSMS data of $\mathrm{m} / \mathrm{z}$ 303(+ve) under different collision energies using ESI-positive ionization

\begin{tabular}{|c|c|c|c|c|c|c|c|c|c|}
\hline Collision energy & \multicolumn{9}{|c|}{ MS-MS fragmentation OF M/Z 303 (+VE) } \\
\hline-5 & 303 & & & & & & & & \\
\hline-10 & 303285 & & & & & & & & \\
\hline-15 & 303285 & & & 195 & & & & & \\
\hline-25 & 303285 & 229 & 207 & 195 & & 153 & & 105 & \\
\hline-35 & 303 & 229 & 207 & 195 & & 153 & & 105 & \\
\hline-45 & 303 & 229 & 206 & 195 & 167 & & 115 & & \\
\hline-55 & 303 & & 206 & 195 & 167 & & 115 & & 43 \\
\hline-60 & 303 & & 206 & & 167 & & 115 & & 43 \\
\hline
\end{tabular}

ESI: Electrospray ionization

Table 5: The effect of shifting reagent on isolated antioxidant compound, i.e., rutin

\begin{tabular}{lllll}
\hline \multirow{2}{*}{ S.No } & \multirow{2}{*}{ CD With shifting reagents } & \multicolumn{3}{c}{ Spectral maxima (nm) } \\
\cline { 3 - 5 } & & Band-I & Band-II & Band-III \\
\hline 1 & $\mathrm{CD}-1$ in Methanol & 256 & 281 & 355 \\
2 & $\mathrm{CD}-1+2$ drops of $2 \mathrm{M} \mathrm{NaOH}$ & 275 & 324 & 422 \\
3 & $\mathrm{CD}-1+2$ drops of $5 \% \mathrm{AlCl}_{3}$ & 278 & 305 & 431 \\
4 & $\mathrm{CD}-1+\mathrm{NaOAc}$ & 271 & 328 & 398 \\
5 & $\mathrm{CD}-1+\mathrm{NaOAc}+\mathrm{H}_{3} \mathrm{BO}_{3}$ & 268 & 300 & 383 \\
\hline
\end{tabular}

testing with 1, 1-diphenyl-2-picrylhydrazyl (DPPH). Extracts which show high antioxidant potential will choose for further isolation and characterization process.

\section{METHODS}

Chemicals and reagents

All the chemicals and glassware (hexane, chloroform, methanol, ethanol, iodine, dimethylsulfoxide (DMSO), double-distilled water, precoated thin-layer chromatography (TLC) silica gel $60 \mathrm{~F}$, and DPPH) used in extraction, antioxidant activity, and isolation are the analytical grade purchased from Ponmani and Co Chemicals, Tiruchirappalli, Tamil Nadu, India.

\section{Plant material collection}

The leaves of M. dubia were collected from in and around areas in Tiruchirappalli, and the plant is authenticated in the Rapinat Herbarium, 


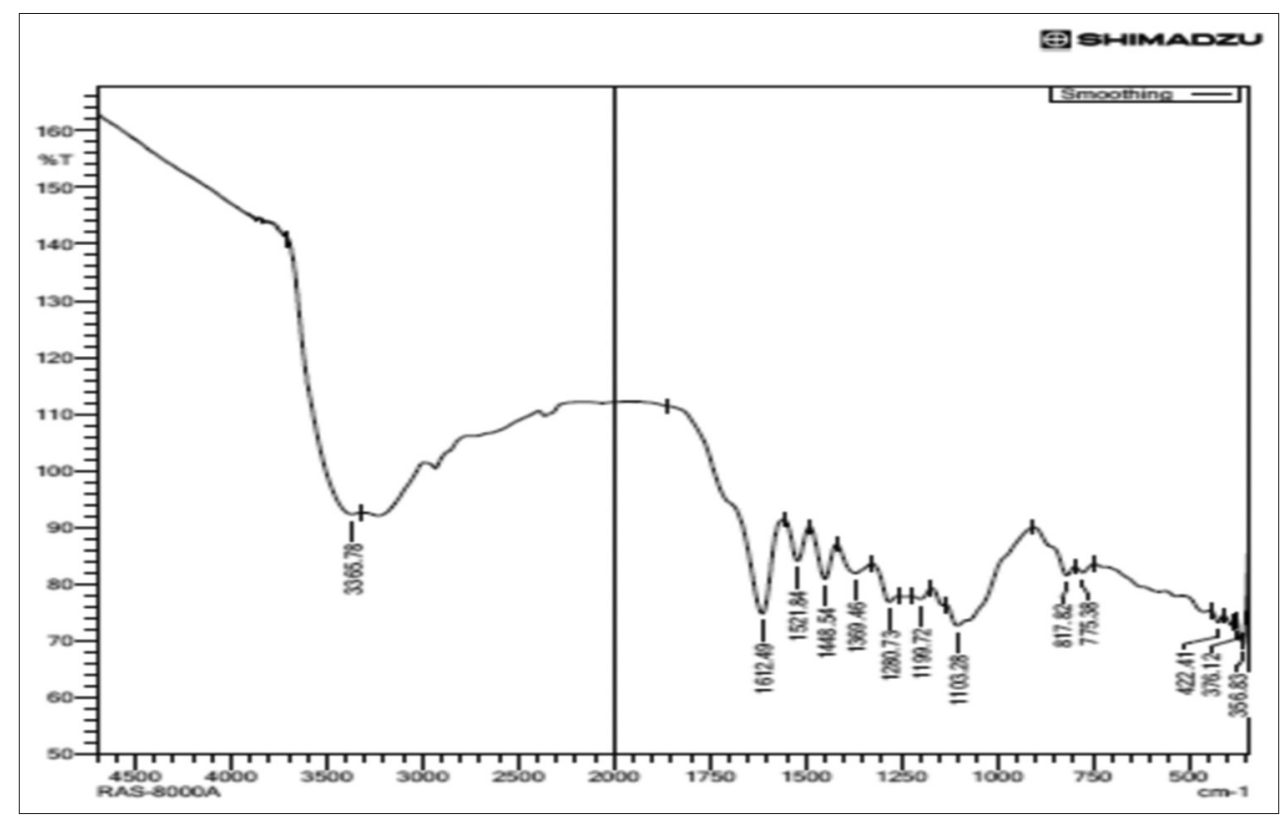

Fig. 10: Fourier-transform infrared spectrum of the antioxidant compound

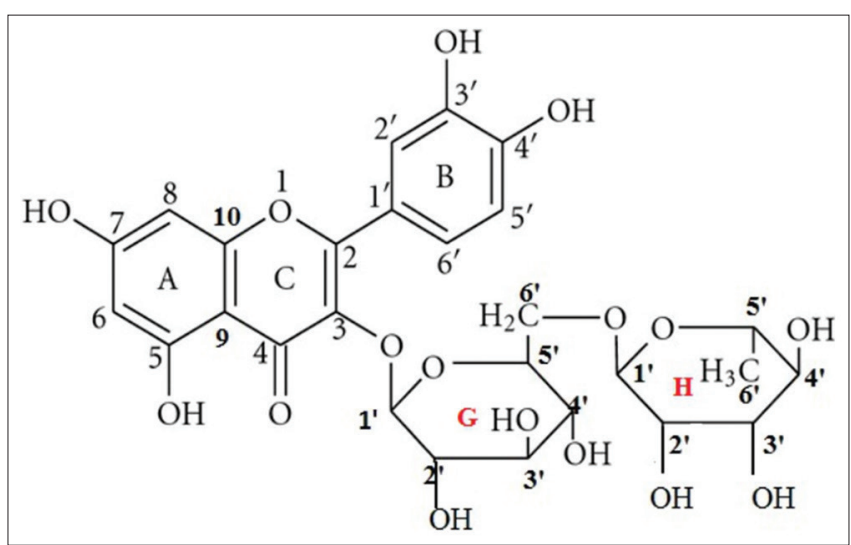

Fig. 11: The structure and numbering of rutin

St. Joseph's College (Autonomous), Tiruchirappalli, Tamil Nadu, India. The voucher specimen number of the M. dubia leaves was GDJ002.

\section{Extraction by Soxhlet extraction method}

$25 \mathrm{~g}$ of a dry powdered form of $M$. dubia leaves was packed inside the Soxhlet thimble, and the thimble was placed on the main chamber of the Soxhlet extractor. Initially, hexane is used as an extraction solvent and it was kept in the round bottom flask. After fitting the condenser, the full setup is placed on the heating mantle. At the stage of the completion of extraction, the final extracts were collected and concentrated at $<40^{\circ} \mathrm{C}$ under reduced pressure using a rotary evaporator. The remaining residual plant material was further extracted with chloroform, ethyl acetate, methanol, water, and $70 \%$ ethanol in the same manner as followed for hexane. All the concentrated extracts were subjected to screening of antioxidant activity [12].

\section{Antioxidant activity by DPPH method}

$0.3 \mathrm{mM}$ solution of DPPH reagent was prepared by dissolving $11.82 \mathrm{~g}$ of DPPH in $100 \mathrm{~mL}$ of ethanol or methanol. Sample stock solution was made by $0.01 \mathrm{~g}$ in $1 \mathrm{~mL}(100 \mathrm{mg} / \mathrm{mL})$ and from that different concentrations were prepared such as $5,25,50,100,200$, and $400 \mu \mathrm{g} / \mathrm{mL}$. $1 \mathrm{~mL}$ of different concentrations of sample solution was mixed with $2 \mathrm{~mL}$ of DPPH reagent and allowed to reach room temperature. 30 min later, the absorbance was recorded at $517 \mathrm{~nm}$ and the percentage of radical scavenging activity, i.e. antioxidant activity was calculated by following standard formulae. Control reading was recorded by $1 \mathrm{~mL}$ of solvent with $2 \mathrm{~mL}$ of DPPH reagent $[13,14]$.

$\%$ of DPPH Scavenged $=(\mathrm{Ab}$ of Control-Ab of test $/(\mathrm{Ab}$ of control $) \times 100)$

$\mathrm{Ab}$ of control - Control Absorbance, Ab of test - Test solution Absorbance

The $\mathrm{IC}_{50}$ values were calculated by linear regression of plots, where the abscissa represented the concentration of the tested sample and ordinated the average percentage of radical scavenging activity.

\section{Isolation and separation of antioxidant}

Extracts (70\% ethanol and methanol extracts) which showed a high percentage of scavenging activity were further taken for the isolation process. Selected extracts were spotted at $2 \mathrm{~cm}$ from the edge of the sheet. The chromatogram is developed in a mixture of a suitable solvent system (trial and error method) and dried at room temperature. The spots were visualized in UV and iodine chamber. The Rf values of the spots were recorded. After that, the TLC plate was dried and sprayed with DPPH reagent, and color changes were noted. The compound with similar Rf value identified in two extracts was pooled together. The active compound (CD-1) was separated by performing column chromatography and purified by preparative high-performance liquid chromatography (HPLC) $[15,16]$.

\section{Characterization of antioxidant}

A separated compound was identified by the phytochemical screening test and further taken for spectral studies for the characterization purpose. The UV-visible absorption spectrum of CD-1 was taken, and methanol was used as a reference solvent. Functional groups are identified by FT-IR, and it was conducted by the minimal amount of CD-1 mixed with spectroscopic grade $\mathrm{KBr}$ and then well-grounded before preparing the pellet. Proton NMR ( $\left.\mathrm{H}^{1}-\mathrm{NMR}\right)$ and Carbon-13 NMR $\left(\mathrm{C}^{13}\right.$ NMR) were analyzed in Bucker NMR 200MHz spectrophotometer. DMSO and TMS were used as the solvent and internal standard, respectively.

\section{RESULTS AND DISCUSSION}

\section{The yield of the extraction}

In the extraction process, hexane extract was yellow in color, chloroform, and ethyl acetate in dark green color. 70\% Ethanol, methanol, and water extracts were brown in color. Regarding yield percentage, water extract shows a high percentage of extract with $11.79 \%$ followed by methanol and $70 \%$ ethanol in the percentage of $6.78 \%$ and $5.69 \%$, 


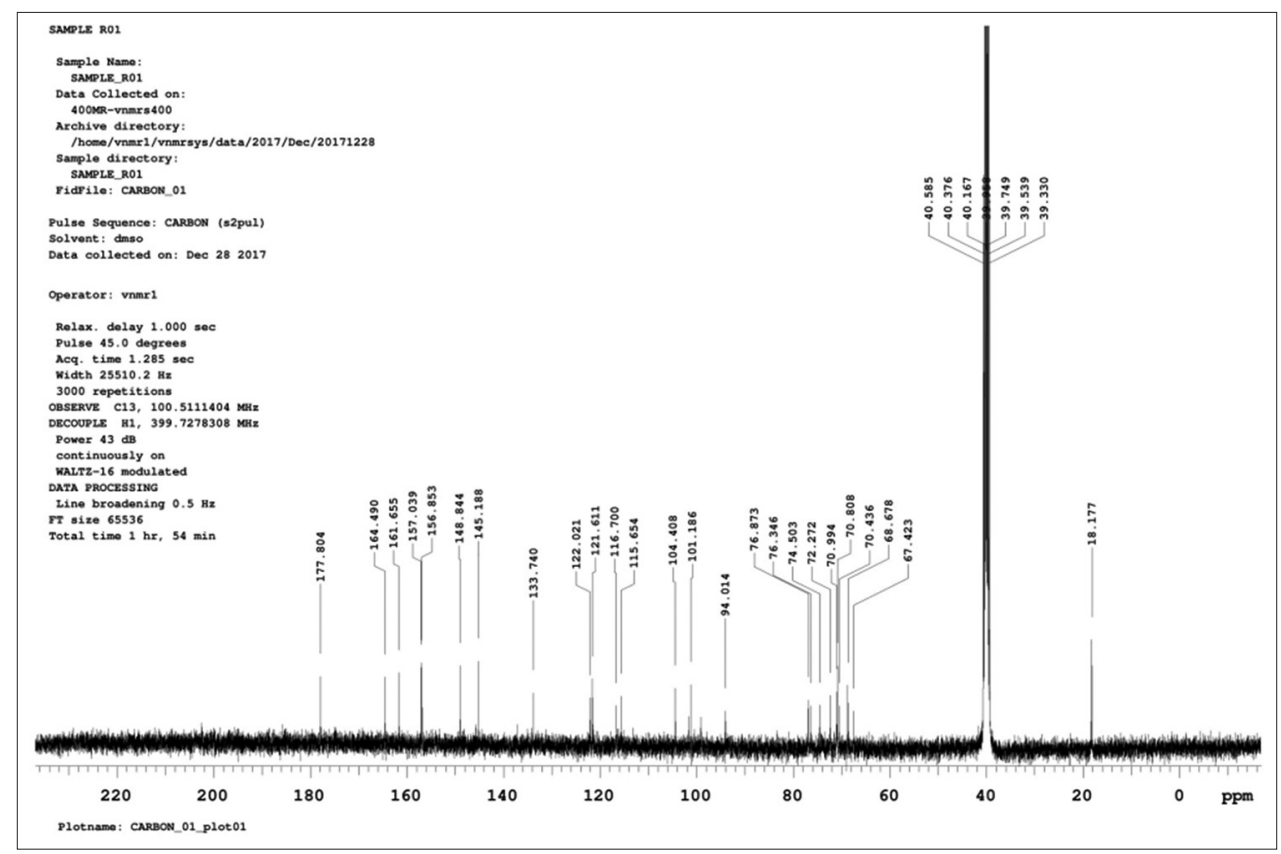

Fig. 12: $\mathrm{H}^{1}$ nuclear magnetic resonance spectra of rutin

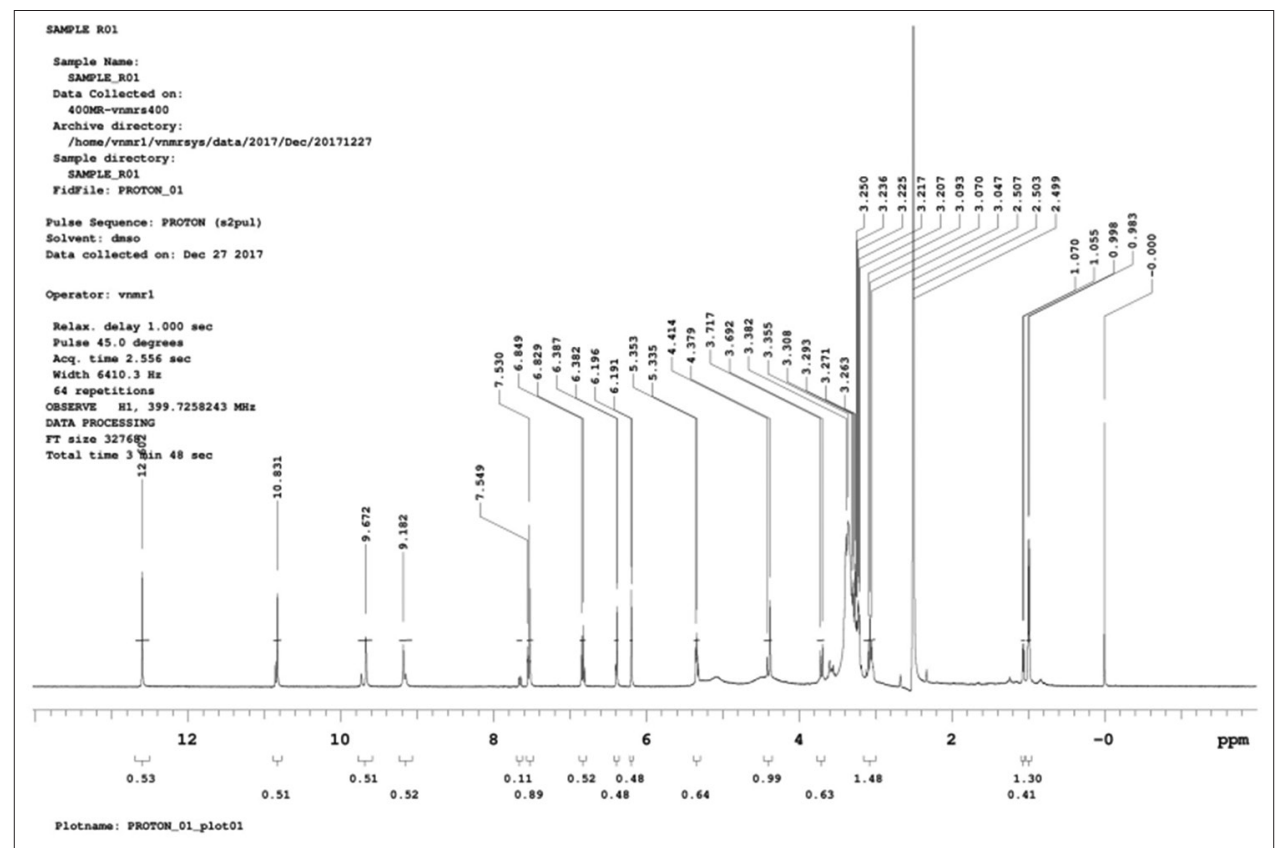

Fig. 13: $\mathrm{C}^{13}$ nuclear magnetic resonance spectra of rutin

respectively. Least yield percentage showed by hexane is $1.52 \%$. The Soxhlet extraction setup was showed in Fig. 1 and the yield percentage is explained in Table 1.

\section{Antioxidant activity by DPPH method}

The effect of radical scavenging potential is examined by discoloration of DPPH reagent, i.e. violet color of the DPPH was changed into yellow after adding extract. Radical scavenging activity on the different extracts of $M$. dubia leaves shows noticeable potential against stable DPPH radical, and it is shown in Table 2. 70\% Ethanol and methanol extracts show greater antioxidant activity compared to others. Beyond the concentration, the $70 \%$ ethanol and methanol extracts show a decrease in the percentage of inhibition, i.e., at $400 \mu \mathrm{g} / \mathrm{mL}$, and it indicates the insufficiency of DPPH reagent due to higher activity of particular extracts. The $\mathrm{IC}_{50}$ value of methanol with $15.61 \mu \mathrm{g} / \mathrm{mL}$ and $70 \%$ ethanol with $17.47 \mu \mathrm{g} /$
$\mathrm{mL}$ are minimum in comparison with the other solvents namely Hexane, Chloroform, Ethylacetate, and Water. 70\% Ethanol and methanol extracts were further taken into further identification and separation process.

\section{Isolation and separation of antioxidant}

Ethanol and methanol extracts were subjected to TLC for the isolation of antioxidant from extracts. In the TLC, the spots were developed in ethyl acetate:acetic acid:water:n-butanol with Rf value of 0.36 , and after spraying the DPPH reagent, the compound responsible for scavenging activity shows bright yellow in the violet background. The spot was collected, and a purified form of antioxidant was obtained by preparative HPLC. The Figs. 2-6 have shown the TLC, column, and HPLC report of antioxidant. The report of HPLC reveals that the retention time of antioxidant is 15.462 , and peak area and the height of the predominant peak of antioxidant are 20,358,456 and 2,618,390, respectively. 


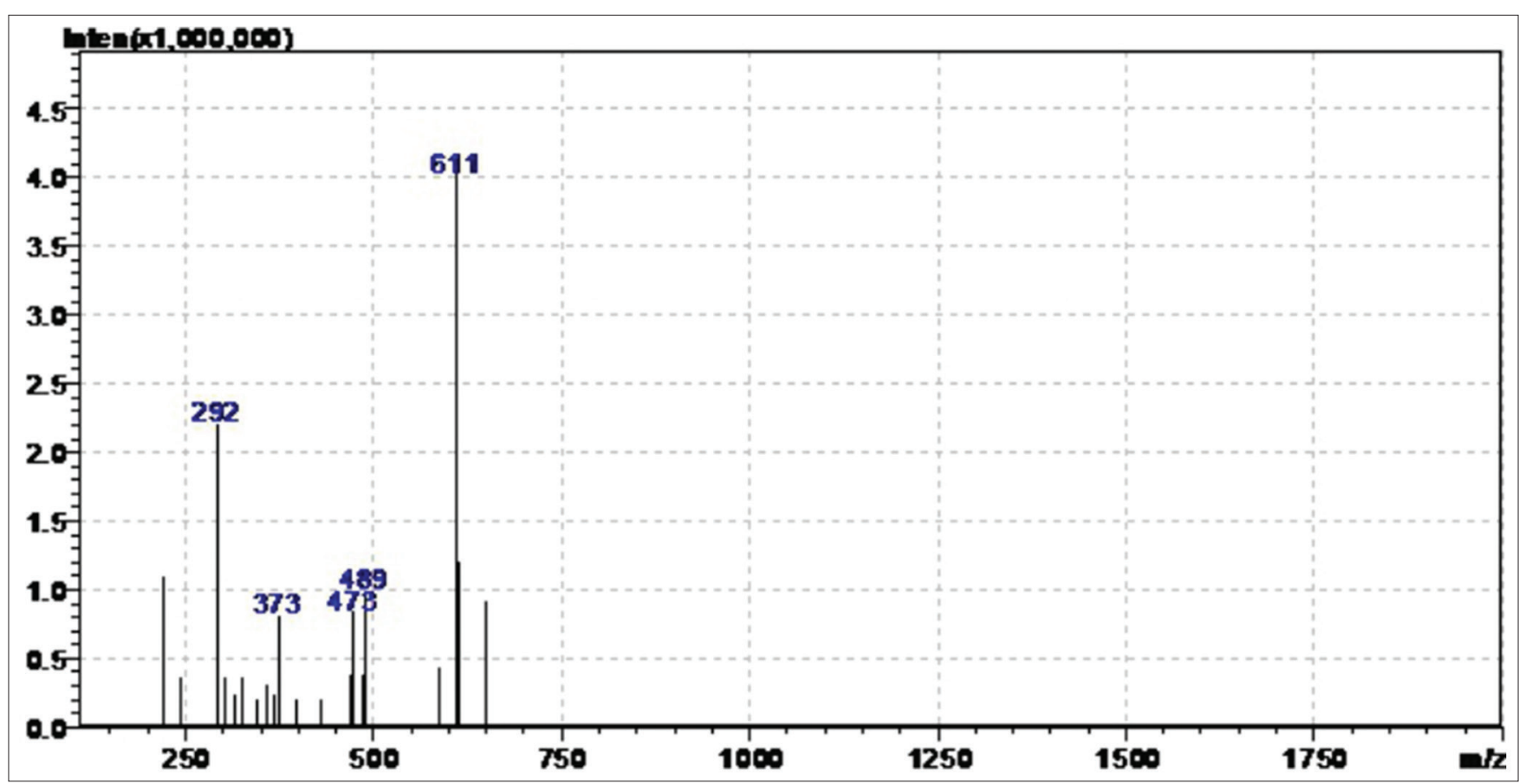

Fig. 14: Mass spectra of flavone-3-rutinoside, 3,3',4',5,7-pentahydroxy i.e., ruti

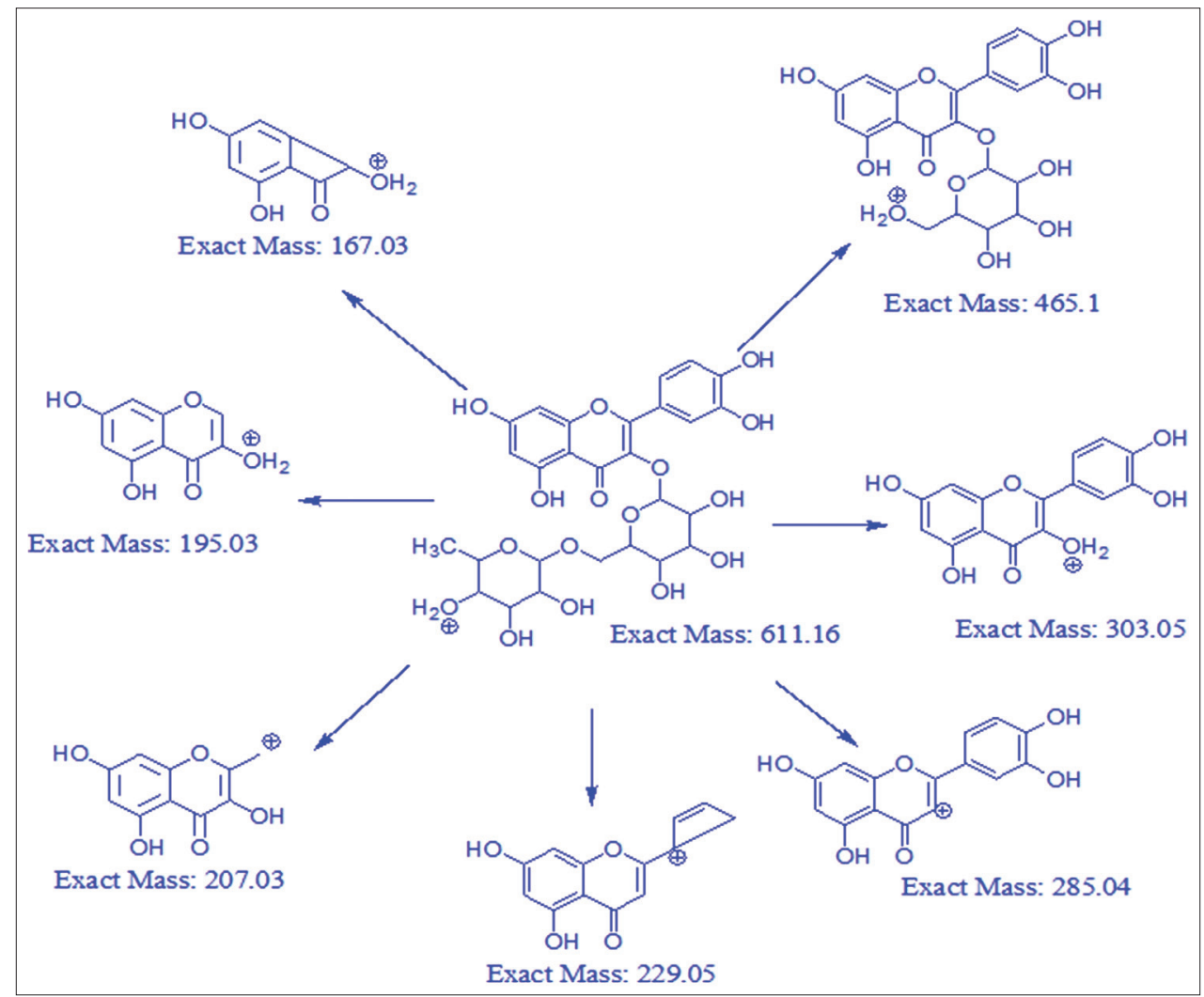

Fig. 15: Mass fragmentation of flavone-3-rutinoside, 3,3',4',5,7-pentahydroxy

\section{CHARACTERIZATION OF ANTIOXIDANT}

Screening test for flavonoid

The antioxidant shows a positive result for flavonoid test and is discussed as follows.
Alkaline reagent test

An aqueous solution of the antioxidant compound was treated with $10 \%$ ammonium hydroxide solution. Yellow fluorescence indicates the presence of flavonoids. 


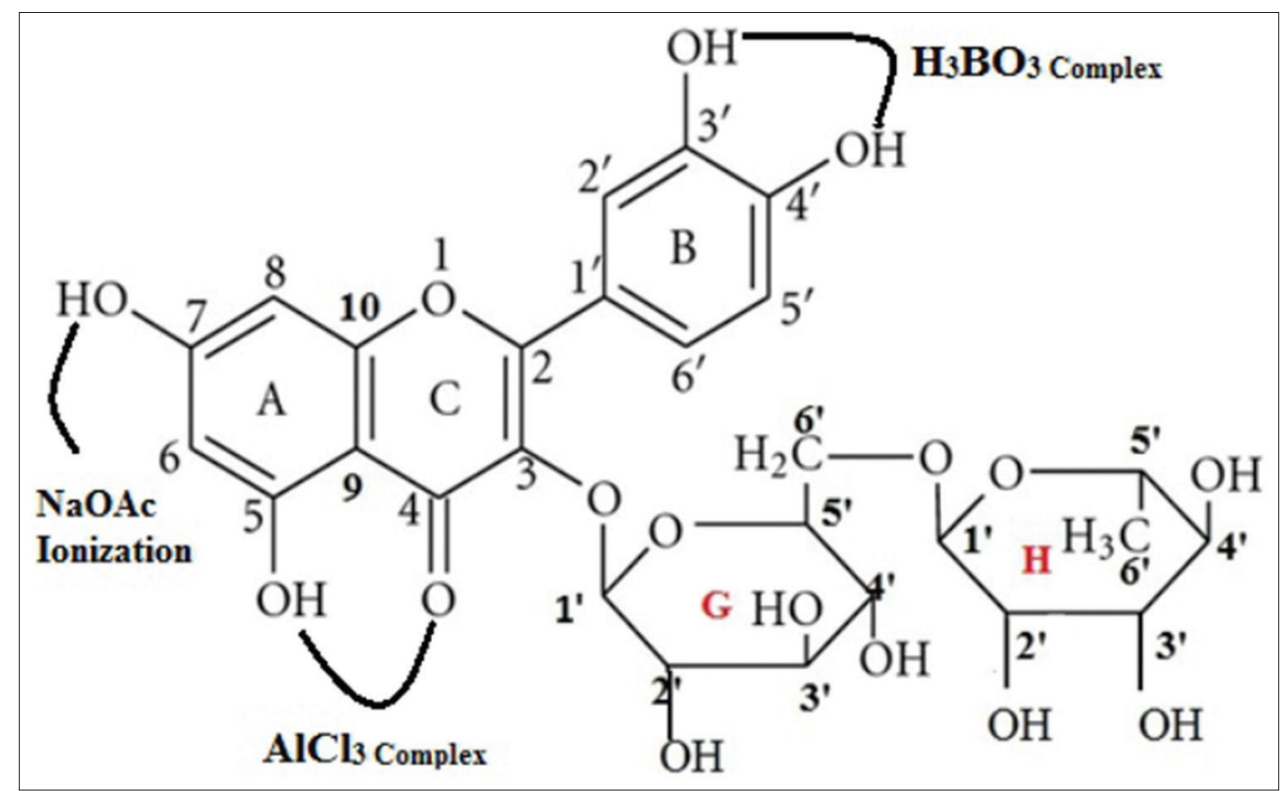

Fig. 16: Complexation of isolated antioxidant with shifting reagents

\section{Magnesium and hydrochloric acid reduction}

The antioxidant compound was dissolved in $5 \mathrm{ml}$ of alcohol, and a few fragments of magnesium ribbon and concentrated hydrochloric acid (dropwise) are added. A color change from pink to crimson red indicates the presence of flavonol glycoside. Figs. 7 and 8 shows the positive result for flavonoids.

\section{UV-visible and FT-IR spectra}

Isolated antioxidant exhibits sign of flavonoid. In general, most flavonoids consist of two major absorption maxima, one of which occurs in the range 240-285 $\mathrm{nm}$ (band-II) and the other in the range 300-400 nm (band-I). Similarly, an absorption spectrum of the compound at $256 \mathrm{~nm}$ (band-II) and $355 \mathrm{~nm}$ (band-1) reveals the presence of the flavonoid nucleus. In FT-IR spectra, peak at $3365 \mathrm{~cm}^{-1}$ gives strong evidence of functionality of the free $\mathrm{OH}$ group in the isolated compound and 1612.49 $\mathrm{cm}^{-1}$ responsible for $\mathrm{C}=0$ stretching frequency. Figs. 9 and 10 are the UVvisible and FT-IR spectrum of the antioxidant compound.

\section{$\mathrm{C}^{13}$ and $\mathrm{H}^{\mathbf{1}} \mathrm{NMR}$ spectra of antioxidant compound}

Proton NMR spectra of the isolated compound give peak at $\delta-12.602$ responsible for $\mathrm{OH}$ proton in $\mathrm{C} 5$ (singlet) similarly 6.196 and 6.191 (d, $1 \mathrm{H}$ in C6), 10.831 (s, OH in C7), 6.387 and 6.382 (d, 1H in C8), 7.530 (dd, $1 \mathrm{H}$ in $\mathrm{C}^{\prime}$ ), 9.182 (s, OH in C3'), 9.672 (s, OH in C4'), 6.849 and 6.829 (dd, $1 \mathrm{H}$ in $\mathrm{C}^{\prime}$ ), and 7.549 (dd, $1 \mathrm{H}$ in $\mathrm{C}^{\prime}$ ), and peak at 2.3 represents DMSO solvent peak and multipeak between $3 \mathrm{ppm}$ and $6 \mathrm{ppm}$ responsible for glycosides linkage in flavonoid nucleus. For the $\mathrm{G}$ ring peak at 5.353 and 5.335 (dd, $1 \mathrm{H}$ in $\mathrm{C}^{\prime}$ ) $), 4.414$ and 4.379 (dd, $\mathrm{H}$ and $\mathrm{OH}$ in $\mathrm{C}^{\prime}$ ), $3.717(\mathrm{td})$ and $3.692(\mathrm{dt})\left(\mathrm{H}\right.$ and $\mathrm{OH}$ in $\mathrm{C}^{\prime}$ ), peak at 3.093 (dd) to $3.047(\mathrm{dd})$ ( $\mathrm{H}$ and $\mathrm{OH}$ in $\mathrm{C4}^{\prime}$ ), 3.308 (td, C5'), 3.293 and 3.271 (dd, 2H, in C6'), for the ring $\mathrm{H}$ peak at 3.382 and 3.355 (d, $1 \mathrm{H}$ in $\mathrm{C}^{\prime}$ '), 3.217 and 3.207 (dd, $\mathrm{H}$ and $\mathrm{OH}$ in $\mathrm{C} 2^{\prime}$ ), peak at $3.250(\mathrm{td})$ to $3.2225(\mathrm{t})$ ( $\mathrm{H} \& \mathrm{OH}$ in C3'), peak at 2.507 to 2.499 (dd, $\mathrm{H}$ and $\mathrm{OH}$ in $\mathrm{C}^{\prime}$ ), 3.263 (qd, $1 \mathrm{H}$ in $\mathrm{C}^{\prime}$ ), and 1.070 and 1.055 (d, 3H in C6'”').

In the case of $\mathrm{C}^{13}$ spectra solvent peak obtained at $40 \mathrm{ppm}$ and peak at 156.853 responsible for $\mathrm{C} 2$ carbon in the same manner 133.740 (C3), 177.804 (C4), 157.039 (C5), 99.5 (C6), 164.490 (C7), 94.014 (C8), 161.655 (C9), 104.408 (C10), 122.021 (C1'), 115.654 (C2'), 145.188 (C3'), 148.844 (C4'), 116.700 (C5'), 121.611 (C6'), for the G ring 101.186 (C1'), 74.503 (C2'), 70.994 (C3'), 72.272 (C4'), 76.346 (C5'), and 67.423 (C6'), for the $\mathrm{H}$ ring 70.808 (C2'), 70.994 (C3'), 70.436 (C4'). 68.678 (C5'), and 18.177 (C6'). The structure and $\mathrm{C}^{13}$ and $\mathrm{H}^{1} \mathrm{NMR}$ spectra of isolated antioxidant compound (rutin) are shown in Figs. 11-13.
Mass spectrum of isolated antioxidant

Mass fragmentation spectrum of CD-1 is shown in Fig. 14, and the energy required for the fragmentation is shown in Table 3. It clearly explains the major parent molecular ion $(M+1)$ peak at $\mathrm{m} / \mathrm{z}=611.16$ responsible for flavone-3-rutinoside, 3,3',4,5,7-pentahydroxy (Rutin). Furthermore, the flavonoid nucleus was fragmented, and its fragments and energy required for the fragmentation electrospray ionization are listed in Table 4. Based on the MSMS fragments obtained from $\mathrm{m} / \mathrm{z}$ $611[+\mathrm{ve}$ ] and $\mathrm{m} / \mathrm{z} 303[+\mathrm{ve}]$, the proposed fragmentation pathway of the compound is displayed in Fig. 15. From the above shreds of evidence, the molecular formula of antioxidant (CD-1) is $\mathrm{C}_{27} \mathrm{H}_{30} \mathrm{O}_{16}$ and accurate molecular weight is found to be 610.5175 .

\section{Effect on CD-1 using shifting reagents}

Shifting reagents such as sodium acetate, boric acid, and alcoholic aluminum chloride were used for the structural diagnosis of flavone-3rutinoside, 3, 3', 4', 5, 7-pentahydroxy. Table 5 undoubtedly explains the structure and its substitution in isolated antioxidant, i.e., rutin.

From Table 5 when adding sodium hydroxide, spectrum was shifted toward the bathochromic region and it is because of free $\mathrm{OH}$ group in C3'. Similarly, adding $\mathrm{AlCl}_{3}$ bathochromic shift due to free $\mathrm{OH}$ in $\mathrm{C} 5$ and for $\mathrm{NaOAc}$, the band -1 was shifted because of $\mathrm{C} 7$ free $\mathrm{OH}$. Finally, adding a mixture of $\mathrm{NaOAc}$ and $\mathrm{H}_{3} \mathrm{BO}_{3}$, the spectrum resulted in a bathochromic shift for complexation at C3' and C4' $\mathrm{OH}$ and it is shown in Fig. 16 [17]. The above effect on shifting reagents confirms the structure and active sides of the antioxidant, i.e. rutin.

\section{CONCLUSION}

This research work mainly investigates the isolation of active antioxidant from the leaf extract of M. dubia. On extraction, water and methanol have high yield; similarly, methanol and 70\% ethanol reveal superior antioxidant activity. In the point of the isolation process, $70 \%$ ethanol and methanol extract have a similar compound with the same $\mathrm{Rf}$ and characteristics properties. The active compound was found to be flavone-3-rutinoside, 3,3',4,5,7-pentahydroxy, and its structure was confirmed by spectral analysis.

Unfortunately, most of the species that are claimed to contain potent antioxidant activity have not been studied in vivo. Therefore, further in vivo studies of this compound are required, and a systematic investigation of this antioxidant-rich flavone-3-rutinoside, 
3,3', 4',5,7-pentahydroxy can be used in the food processing industry and as preventive for many diseases in the field of medicine. In general, after isolation, the biological activity of the compounds was tested, but in our work initially, the antioxidant activity of the different extracts was identified after identifying best extract, and further isolation and characterization process was carried out. This work is one of the ways for finding and isolating useful bioactive compounds in a similar manner for the rest of the antioxidants present in the leaves. This approach findings may lead to a different area of research in this field.

\section{ACKNOWLEDGMENT}

We thank our professor Mr. T. Antony Diwakar Chandran, Head and Assistant Professor in Biochemistry, St. Joseph's College (Autonomous), Tiruchirappalli, India, who constantly provide facility to carry out the antioxidant assay in his institute. We are grateful to Mr. A. Benno Susai Vijayakumar, Assistant Professor in Biochemistry, St. Joseph's College (Autonomous) for his professional guidance on antioxidant assay and IC $\mathrm{C}_{50}$ value calculations for my reports. We thank our institute and Principal Dr. Sr. Christina Bridget, Holy Cross College (Autonomous), Tiruchirappalli, India, for providing laboratory facility to perform our research work.

\section{CONFLICTS OF INTEREST}

The authors have declared no conflicts of interest.

\section{REFERENCES}

1. Available from: https://www.en.wikipedia.org/wiki/Antioxi dant/30.06.2018.

2. ChoiCW,KimSC,Hwang SS, ChoiBK,AhnHJ,LeeMY, etal.Antioxidant and free radical scavenging capacity between Korean medicinal plants and flavonoids by assay-guided comparison. Plant Sci 2002; 163:1161-8.

3. Sindhi V, Gupta V, Sharma K, Bhatnagar S, Kumari R, Dhaka N. Potential applications of antioxidants-a review. J Pharm Res 2013;
7:828-35.

4. Hajhashemi V, Vaseghi G, Pourfarzam M, Abdollahi A. Are antioxidants helpful for disease prevention? Res Pharm Sci 2010;5:1-8.

5. Mensor LL, Menezes FS, Leitão GG, Reis AS, dos Santos TC, Coube CS, et al. Screening of Brazilian plant extracts for antioxidant activity by the use of DPPH free radical method. Phytother Res 2001; $15: 127-30$

6. Available from: https://www.medlineplus.gov/antioxidants. $\mathrm{html} / 30.06 .2018$

7. Suresh K, Harinath M, Sachin M, Sameer N, Sachin S, Raviraj K. Phytochemical screening and in-vitro antioxidant activity of Memecylon umbellatum root extracts. World J Pharm Pharm Sci 2013;2:5988-96.

8. Kähkönen MP, Hopia AI, Vuorela HJ, Rauha JP, Pihlaja K, Kujala TS, et al. Antioxidant activity of plant extracts containing phenolic compounds. J Agric Food Chem 1999;47:3954-62.

9. Rahman MA, Rana MS, Zaman MM, Uddin SA, Akter R. The antioxidant, antibacterial and cytotoxic activity of the methanol extract of Urtica crenulata. J Sci Res 2010;2:167-77.

10. Chakraborty AP, Roy H, Bastia S. Evaluation of antioxidant activity of the leaves of Eupatorium odoratum Linn. Int J Pharm Pharm Sci 2010; 2:77-9.

11. Krishnaiah D, Sarbatly R, Nithyanandam R. A review of the antioxidant potential of medicinal plant species. Food Bioprod Process 2011; $89: 217-33$

12. Yadav RN, Agarwala M. Phytochemical analysis of some medicinal plants. J Phytol 2011;3:10-4.

13. Ordon $\simeq \mathrm{ez} A A$, Gomez JD, Vattuone MA, Isla MI. Antioxidant activities of Sechium edule (Jacq.) Swartz extracts. Food Chem 2006;97:452-8

14. Charoonratana T, Settharaksa S, Madaka F, Sak TS. Screening of antioxidant activity and total phenolic content in Raphanus sativus pod. Int J Pharm Pharm Sci 2014;6:224-6.

15. Raaman N. Phytochemical Techniques. New Delhi: New India Publication Agency; 2006. p. 275-86.

16. Sharma V, Paliwal R. Isolation and characterization of saponins from Moringa oleifera (moringaeceae) pods. Int J Pharm Pharm Sci 2014;5:179-83.

17. Harborne JB. A Guide to Modern Techniques of Plant Analysis. $2^{\text {nd }}$ ed. USA: Kluwer Academic Publisher; 1998. p. 75-7. 